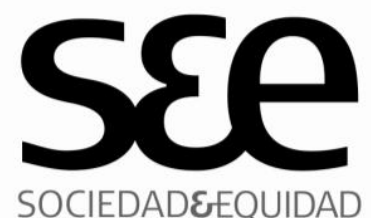

SOCIEDADEEQUIDAD

\section{La disputa por la legalización del aborto en Argentina Los usos políticos del Nunca Más}

The dispute about the legalization of abortion in Argentina

The political uses of Nunca Más

\section{Nombre: \\ Filiación: \\ País: \\ Correo:}

\author{
Pablo Gudiño Bessone ${ }^{(1)}$ \\ IDES/CONICET \\ Argentina \\ pablo_bessone7@hotmail.com
}

\title{
RESUMEN
}

En este ensayo abordamos los modos en que el discurso de la memoria de la última dictadura militar en Argentina (1976-1983) se hace presente en el marco de la disputa por la legalización del derecho al aborto. Prestamos atención a la forma en que el significante político del "Nunca Más" es reapropiado por la Iglesia Católica, los colectivos sociales pro-vida y sectores pertenecientes a la corriente feminista con el objetivo de legitimar sus argumentos en relación a la defensa de la vida. El legado político del "Nunca Más" se ha instalado en el imaginario social y cultural de nuestro país. Su estructura narrativa y sus significantes políticos son objeto de múltiples resignificaciones para la elaboración de demandas de justicia en el presente. En este sentido, pretendemos ver cómo el discurso del "Nunca Más"permanece enlazado a la lucha por la defensa del derecho a la vida y se transforma en un emblema político y cultural en disputa.

\section{PALABRAS CLAVES}

Aborto, Iglesia Católica, mujeres, memoria, Nunca Más.

\footnotetext{
${ }^{1}$ El autor es Licenciado en Ciencia Política por la Universidad Nacional de Villa María (UNVM). Doctorando en Ciencias Sociales por la Universidad Nacional de General Sarmiento/ Instituto de Desarrollo Económico y Social (UNGS-IDES). Becario de Posgrado del Consejo Nacional de Investigaciones Científicas y Técnicas (CONICET). Becario del Núcleo de Estudios sobre Memoria/ IDES.
} 


\section{ABSTRACT}

In this paper we address the ways in which the discourse of memory of the last military dictatorship in Argentine (1976-1983) is present the dispute about the legalization of abortion. We pay attention to the way in which the political signifier of Nunca Más is reappropriated by the Catholic Church, the pro-life social groups and sectors within the feminist movement in order to legitimize their arguments regarding the defense of life. The political legacy of Nunca Más has been installed on the social and cultural imaginary of our country. Its narrative structure and its political signifiers are objects of multiple resignifications for the production of demands of justice in our days. In this sense, we try to see how the discourse of Nunca Más remains connected to the struggle for the defense of the right to life and becomes a political and cultural emblem in dispute.

\section{KEYWORDS}

Abortion, Catholic Church, women, memory, Nunca Más.

El presente ensayo tiene como propósito abordar cómo los significantes discursivos de la memoria de la última dictadura militar en la Argentina (1976-1983) revisten en el presente una dimensión social moralizante que torna propicios sus intentos de reapropiación y uso político. En particular, nos interesa la forma en que el legado cultural y político del “Nunca Más" es resignificado en el presente, es decir, el modo en que éste se constituye en una clave narrativa en la que una proliferación de actores sociales inscriben sus argumentos en torno a la legalización o no del aborto.

Por un lado, hacemos alusión al accionar político de la Iglesia Católica así como de las entidades laicas y militantes pro-vida, quienes refieren al "no nacido" como los nuevos inocentes desaparecidos en democracia. En este sentido, la memoria del pasado de la dictadura es instrumentada a fin de generar efectos normativos y de criminalización en las mujeres que demandan por el derecho a la autodeterminación del propio cuerpo.

Por otro lado, nos referimos al Colectivo Feminista de Mujeres Juana Azurduy quienes en el marco de la "Campaña Nacional por el Derecho al Aborto Legal, Seguro y Gratuito" irrumpen en el espacio público con sus demandas haciendo uso del significante político del Nunca Más. Dicho significante no sólo es activado por este colectivo feminista como una consigna política a partir de la cual adquieren identidad sus reclamos por el "derecho a la vida de la mujer gestante", sino también 


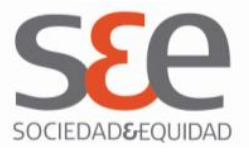

como un dispositivo discursivo mediante el cual se pretende interpelar a la sociedad acerca de un sin número de mujeres que fallecen a causa de la práctica clandestina del aborto.

En síntesis, si bien el Nunca Más ha sido en su momento el resultado de los intentos de elaboración de una memoria colectiva mediante la cual se pretendió darle forma y encuadramiento a los procesos de rememoración del pasado reciente en la Argentina; este ensayo no aborda a la memoria colectiva como un objeto epistemológico en sí mismo sino desde la referencia y reapropiación que de la construcción de ese pasado hacen en el presente distintos actores sociales. En otras palabras, nos interesa el modo en que el Nunca Más es activado en el escenario actual como un significante político y discursivo en disputa.

\section{El Informe Nunca Más y la construcción de una memoria colectiva}

La Comisión Nacional sobre la Desaparición de Personas (CONADEP) fue creada por el gobierno argentino en 1983 con el objetivo de aclarar e investigar la desaparición forzada de personas producidas durante la dictadura militar en Argentina. Ello originó el Informe Nunca Más -también popularmente conocido como el "Informe Sábato"- que fue finalmente publicado en septiembre de 1984. Ante todo, el Nunca Más emerge como la construcción organizada de un cúmulo de relatos y testimonios a fin de darle sentido a un escenario social y político pasado atravesado por la irrupción de la violencia. ${ }^{2}$

Dicho informe, se hizo presente en el espacio público como algo más que la narración y ordenamiento de las experiencia y testimonios sobre los crímenes cometidos en el contexto de la dictadura; surgió como la construcción política de "una prueba en el sentido de una intervención que se orientaba a someter esos acontecimientos a la acción de la ley" (Vezzetti, 2002: 28). En otras palabras, como el devenir de una operatoria política que preparaba el terreno para lo que luego fue el denominado “Juicio a las Juntas" en 1985; donde el mismo Informe Nunca Más sirvió como base y sustento para el accionar de los tribunales de justicia.

\footnotetext{
${ }^{2}$ La CONADEP fue conformada luego de que la democracia fuese restituida en la Argentina en 1983. El objetivo de dicha comisión ha sido el propósito de iniciar una investigación sobre el destino de los miles de desaparecidos durante el gobierno militar. Tras recabar un número importante de testimonios, la comisión logró alcanzar evidencias acerca de los eventos relacionados con personas desaparecidas y entregó dicha información al presidente de entonces el Dr. Raúl Alfonsín. El objetivo de la investigación no consistía en el propósito de determinar responsabilidades sino de documentar -de modo objetivo- la cronología y sucesión de los eventos. Con la intensión de preservar la objetividad de los testimonios, el Poder Ejecutivo determinó que la comisión estuviera conformada por personalidades con prestigio nacional e internacional, elegidos por su compromiso en la lucha por los derechos humanos. El informe arribó como resultado el intento de esclarecimiento de miles de casos de abducción, desaparición, tortura y ejecuciones. Se compilaron alrededor de 50.000 páginas de documentación. Un tiempo más tarde un resumen del informe fue publicado con el título Nunca Más.
} 
Por memoria colectiva Maurice Halbwachs (2005) considera el resultado de una construcción social que -desde el presente- proporciona estabilidad y fijeza a la experiencia y el recuerdo del pasado (Ramos, 1989). En ese sentido, el autor se interesa por aquellos puntos de referencia que estructuran a nuestra memoria social sobre los acontecimientos y pretende demostrar no sólo el carácter social de la memoria -lo que recordamos- sino el cómo la sociedad recuerda. Pero, si bien Halbwachs interpreta que la fijación de la memoria nunca es definitiva dado que permanece expuesta a las múltiples reconstrucciones que de la misma se hacen en el presente, lejos está de ver en esa memoria colectiva un intento de imposición político-simbólica (Pollak, 2006).

En base a esto, podemos conjeturar que el Nunca Más ha sido en nuestro país el derivado del deseo de construcción de una memoria colectiva organizada por parte del Estado que -en medio de un clima de amenaza y posible vuelta a la inestabilidad política- impuso la imagen de una sociedad inocente que en el pasado había sido víctima del accionar político y violento desencadenado por la existencia de dos extremos ideológicos en conflicto: “Durante la década del 70' la Argentina fue convulsionada por un terror que provenía tanto desde la extrema derecha como de la extrema izquierda [...] En cuanto a la sociedad, iba arraigándose la idea de la desprotección, el oscuro temor de que cualquiera, por inocente que fuese, pudiese caer en aquella infinita casa de brujas" (Sábato, 1984: 3-4).

Estudiar la imposición de las memorias colectivas, como lo es la construcción de una memoria arraigada en la denominada o popularmente conocida "Teoría de los dos Demonios", nos obliga a prestar atención a las formas en que se pretendió desde las instituciones oficiales penetrar en el tejido social mediante una narrativa inteligible que actuara como factor explicativo y de interpretación de los acontecimientos del pasado reciente ${ }^{3}$.

\footnotetext{
${ }^{3}$ La "teoría de los dos demonios" es considerada como la labor de imposición de un sentido sobre el pasado mediante el que se pretende dar a reflexión sobre la existencia de una sociedad inocente víctima del conflicto político desatado entre dos espectros ideológicos en disputa: Las Fuerza Armadas y la guerrilla. Dicha teoría conduce a la conclusión sobre el desenlace de una violencia análoga que recayó injustamente sobre una sociedad que en su conjunto ignoraba lo que sucedía (Levín, 2005). Esta versión de los "dos demonios" no sólo tuvo su puesta en escena durante el proceso del "Juicio a las Juntas" (1985) -donde se trató de comprobar los excesos cometidos en medio de una "guerra sucia"- sino también en la construcción de múltiples relatos sociales que se fueron haciendo presentes en esos días como forma de reflexionar acerca de los acontecimientos sucedidos durante la dictadura. A modo de ejemplo, la película La Historia Oficial (1885) y el libro -también película- La Noche de los Lápices (1986); muestran el retrato de una sociedad inocente que ignoraba lo que pasaba a su alrededor o que elegía no saber por miedo (Cerruti, 2001; Lvovich y Bisquert, 2008).
} 


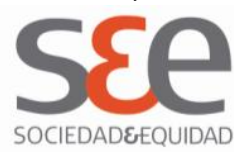

Dicha labor de encuadramiento de la memoria se hizo presente en el trayecto del Informe Nunca Más cuyo reflejo está en la caracterización de una sociedad inocente ajena a la violencia y al conflicto político del entonces. Una ciudadanía indefensa que, escoltando a esa búsqueda y propuesta de pacificación por parte del Estado, abogaba por el tránsito definitorio hacia la consolidación de la democracia y la recuperación del Estado de Derecho. ¿Qué ha sido ese trabajo de encuadramiento de la memoria en el Nunca Más sino el intento de imposición de una verdad sobre los acontecimientos, la elaboración de un relato basado en el horror cuyo objetivo fue sacudir a la conciencia pública? Esta labor de encuadramiento no fue sino el intento de creación de una memoria ejemplar donde -por intermedio de la exaltación del horror- se pretendió imponer en la sociedad el mandato de recordar para no repetir y se obligó, por cierto, a sumar compromisos con el Estado en la búsqueda de una pacificación que en el fondo escondía el accionar de una estrategia despolitizante.

Mediante la exacerbación de testimonios basados en el horror, el Nunca Más se hizo presente como un relato en el que la suerte de los desaparecidos se redujo a su condición de víctimas inocentes, quedando así deslucido su compromiso y accionar político-militante: "[...] la implantación de una imagen despolitizada del conflicto [esto es] la elaboración de políticas de la memoria en esa clave” (Jelin, 2007: 328). En este sentido, el testimonio dado por los testigos tendió a desprenderse de su experiencia y subjetividad política para adquirir la forma de la evidencia o prueba jurídica. De este modo, se tendió a la construcción de una verdad y representación unitaria sobre las desapariciones que -mediante la creación de un relato hegemónico y de una narración colectiva sobre lo acontecido- dio lugar a la posibilidad de trascender la individualidad de cada caso en particular concluyendo en el devenir de una memoria pública. En cierto modo, no resulta sorprendente que en esta labor de encuadramiento de la memoria colectiva los testimonios no hayan sido abordados como instrumentos de restitución de identidad de los sujetos, sino solamente como “[...] relatos factuales, limitados a una función informativa” (Pollak, 2006: 55) ${ }^{4}$.

La tarea de encuadramiento de la memoria envuelta en la idea de una sociedad víctima del accionar indiscriminado de la violencia ha sido construida sobre la base de una narrativa humanitaria de las desapariciones cuyo propósito fue su propia socialización (Crenzel, 2005, 34; 2008; 107). Ahora bien: ¿qué ha sido el Nunca Más sino el intento de inscripción social de un relato estructurante a partir del cual de modo performativo- se pretendió darle forma a los actos de rememoración e interpretación del pasado? Plantearnos como propósito este interrogante, no sólo nos permite abordar a la memoria colectiva como a un "objeto dado" sino también

\footnotetext{
${ }^{4}$ Para Michael Pollak (2006), el tipo de testimonios en situación oficial -como lo es en este caso la lista de testimonios presentado en el marco de la CONADEP- se caracterizan por la tendencia a la generalización de la experiencia individual. En ese contexto, la persona del testigo tiende a dilucidarse tras la centralidad que se le otorga al relato de los hechos. Esto es considerado por el autor como el clima de un escenario impersonal y constrictivo en el que la subjetividad de los actores queda restringida a los objetivos de construcción de una verdad o evidencia jurídica.
} 


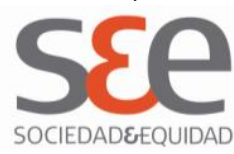

prestar atención a los efectos de su lineamiento y construcción discursiva (Jelin, 2002). En la medida en que toda labor de encuadramiento de la memoria se orienta a los fines de revestir de un sentido unilateral al pasado, dicha operación adquiere con el devenir del tiempo- cierto grado de centralidad en el modo en que los actores sociales hacen un uso político y cultural de su recepción. No debemos considerar a esta labor de encuadramiento de la memoria explayada en el Nunca Más exclusivamente en su propósito de atribuirle una explicación inteligible a los hechos del pasado. Más bien, debemos prestar atención al modo en que su dimensión performativa -en el presente- provoca ciertos excesos que se reflejan en la forma en que los "nuevos" acontecimientos tienden a ser inscriptos en sus estructuras hegemónicas de sentido.

El Nunca Más produjo un verdadero acontecimiento reordenador de las significaciones del pasado, a la vez que impuso en la sociedad una marca simbólica y de referencia a las iniciativas de memoria (Vezzetti, 2002). Una diversidad de relatos y testimonios basados en el horror y en el desencadenamiento de una violencia sin límites, dio lugar al devenir de un juicio social y colectivo que instaba no solo por el esclarecimiento de la "verdad" y el "castigo" a los responsables sino también por la no repetición del pasado. A propósito, el estremecedor suceder de los testimonios iba acompañado de una alta densidad y carga emotiva que, con el tiempo, se fue insertando en lo más hondo del sentimiento público. Pero si bien en su momento el Nunca Más llevó como trasfondo el objetivo de imposición de una estrategia despolitizante, cabe preguntarnos en nuestros días cuál es el lugar que dicho legado deja a su posible y potencial efecto de politización.

Por cierto ¿puede decirse que es hoy el Nunca Más un objeto de sacralización política, un dispositivo y discurso social moralizante que estructura y reviste de significado a una proliferación de demandas políticas y sociales de justicia? Con el transcurrir de los años, los acontecimientos de la dictadura dejaron de ser el lugar de una singularidad finita y radical toda vez que sus significaciones fueron adquiriendo protagonismo con el paso del tiempo. En síntesis, existen múltiples formas de entender a la memoria y de ejercerla. Éstas se vinculan tanto con los procesos de su reconstrucción como con los usos políticos que se le dan a sus significaciones. En este sentido, la noción de "usos políticos" de la memoria adquiere relevancia no sólo en la representación del pasado como discurso; sino también en el lugar que ese pasado adquiere como motor de acción para las reivindicaciones de justicia en el presente y el futuro (Rousso en Feld, 2000). En la actualidad, los usos que se hacen del Nunca Más son "usos morales". En ello radica la dimensión social interpelativa de dicho legado, el Noli Me Tangere de la política.

El Noli me tangere corresponde a uno de los episodios del Evangelio de San Juan, pasaje en el que Jesucristo dirige sus palabras a María Madgalena luego de su resurrección y emprende su retirada. Habla para decir que ya no está allí donde se cree que está, que está ya en otra parte, estando sin embargo muy presente. Noli me 


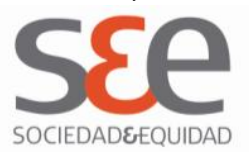

tangere -"no me toques", "no quieras tocarme"- evoca una prohibición de contacto, un peligro, una advertencia, dado que el mero contacto con el cuerpo de Cristo resucitado socavaría en una falta, tornaría vulnerable su carácter sagrado, lo retornaría al suplicio y el sufrimiento. Para Jean-Luc Nancy (2006), el Noli me tangere es una frase que "toca", un punto que afecta significativamente, incluso aislado del contexto mismo en el que se origina. A nuestros días, podríamos decir que el Nunca Más ocupa en la esfera pública el lugar de un Noli me tangere. Una narrativa significante que -tras haberse estructurado en los testimonios del horror- se ha convertido en un emblema moral; un legado que en cierto modo roza los límites de lo sacro, de lo "intocable". Una clara demostración de ello está en el "uso" político que de dicho significante emprenden una multiplicidad de actores sociales a fin de fortalecer sus demandas de justicia. El Nunca Más trae consigo mismo una alta carga de sensibilidad social. Se ha ido transformando con el paso del tiempo en una especie de mandato moral y ético; se fue arraigando en las bases más sólidas de nuestra cultura política.

Iglesia Católica y feminismo: el aborto y las resignificaciones discursivas del Nunca Más

Con los años, el Nunca Más y la alusión a la violación de los derechos humanos en la Argentina, se ha ido constituyendo en una clave político y cultural de lectura por medio de la cual una heterogeneidad de actores sociales reconfiguraron sus demandas de justicia (Pereyra, 2005; Crenzel, 2010). En este sentido, y a partir de la experiencia social y colectiva que marcó la dictadura en nuestro país, podemos decir que la labor de encuadramiento de la memoria en el Nunca Más -el retrato de una sociedad inocente víctima de la violencia indiscriminada- se hace presente en el ejercicio de un doble movimiento. Por un lado, en la preocupación por mantener latente las escenas del horror que caracterizaron al transcurso de ese pasado dictatorial (recordar para no repetir). Por el otro lado, en el "uso político" y en la interpelación moralizante que la activación de dicho pasado genera con relación a los propósitos inmediatos del presente y los deseos de proyecciones futuras. En este sentido, el presente apartado parte de las siguientes incógnitas: ¿En qué medida podemos reconocer en el legado significante del Nunca Más la inscripción políticosimbólica de la disputa que la Iglesia Católica, los militantes pro-vida y las feministas mantienen respecto a la legalización del aborto? ¿Cuál es la apropiación que los actores sociales hacen del encuadramiento de la memoria en la imagen de una sociedad inocente, y de qué modo la activación de la misma en esa clave rodea a la disputa que dichos actores emprenden en torno a la defensa de la "vida"?

En cierto modo, el "uso político" que la Iglesia Católica, los militantes provida y el colectivo feminista le otorgan al Nunca Más debe ser visto como la activación de una estrategia política orientada a ganar adeptos; como el intento de interpelar a la sociedad con el tema del aborto trayendo a colación los recuerdos de un pasado atravesado por el horror y la violencia. En ello podemos observar la 


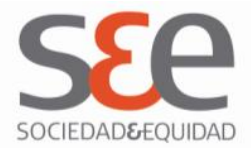

presencia en el espacio público de un discurso político que intenta ir acompañado de la carga moral que la memoria ha ido adquiriendo durante los años de democracia; la conversión de ésta en un objeto de disputa y lucha por su reapropiación dado el rol significante que su activación genera. En tanto marca que se inscribe en el espacio de lo colectivo, la memoria no existe como fenómeno estático sino que adquiere permanencia en el modo en el que lo acontecido va siendo articulado con los hechos actuales (Calveiro, 2006). Uno de los fenómenos culturales y políticos más trascendentes de nuestro último tiempo, ha sido el surgimiento del Nunca Más cómo vehículo de memoria; narrativa que se ha ido instalado en el imaginario colectivo como un dispositivo de interpretación y lectura del pasado. Dicho metarrelato se fue intensificando con el tiempo; a tal punto que actúa como tropos de las demandas de

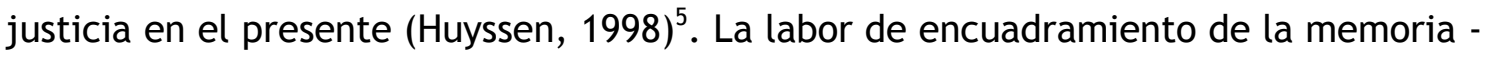
en este caso la construcción imaginaria de una sociedad inocente- sólo tiene validez en la medida en que, con el tiempo, haya sujetos que actúen de acuerdo a lo que esa memoria elabora y se encarga de transmitir.

Práctica política de interpelación moral, el modo con que la Iglesia Católica y los militantes pro-vida establecen un juego de asociación entre los desaparecidos durante la dictadura y los "niños por nacer", tiene como objetivo generar efectos de estigmatización y creación de culpa sobre el conjunto de aquellos actores que promueven la legalización del aborto. En este sentido, el aborto es caracterizado como una práctica criminal y genocida; en ello radica su consideración como la interrupción arbitraria de la vida de un ser indefenso e inocente. Para la Iglesia Católica y las organizaciones laicas pro-vida, la legalización del aborto induce a la legitimación del crimen a la vez que suscita un retorno hacia los tiempos del terrorismo de estado. Implica una desvalorización del derecho a la vida del "no nacido"; un "pisoteo" hacia el primero de los Derechos Humanos: "Aprobar el aborto es un delito de lesa humanidad contra inocentes" (Bredice et al., 2007). ${ }^{6}$ "No hablamos de la ley divina 'No matarás', hablamos de funcionarios del Estado que ni siquiera cumplen la Constitución que han jurado o las leyes que están vigentes y promueven, cuando no celebran, el exterminio o desaparición forzada de bebés humanos en verdaderos actos de terrorismo de Estado" (Castellanos et al., 2010). ${ }^{7}$

\footnotetext{
${ }^{5}$ En su obra En busca del futuro perdido. Cultura y memoria en tiempos de globalización, Andreas Huyssen aborda la noción de tropos discursivos haciendo alusión al modo en que la memoria del Holocausto se hace presente en el pensamiento posmoderno; abocándose a situaciones específicas más allá de su distancia con el tiempo. En nuestro caso, nos interesamos en ver cómo la construcción discursiva de la memoria en el Nunca Más no sólo se limita a su calidad de acontecimiento histórico. Nos preocupamos también por el modo en que dicho legado es activado como una metáfora para la lectura de situaciones presentes. En otras palabras, el lugar que ocupa el Nunca Más en el marco de la emergencia de una "cultura de la memoria" que no sólo se restringe a la tarea de revisión de los hechos del pasado; sino también a la forma en que la memoria es activada como un mecanismo político para la ampliación de los derechos civiles de ciudadanía.

${ }^{6}$ Monseñor Reinaldo F. Bredice, obispo de Santa Rosa, La Pampa, Argentina.

${ }^{7}$ Roberto Castellanos, presidente ONG Pro-Vida Argentina.
} 


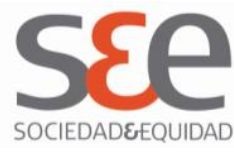

Estrategia de articulación discursiva, la Iglesia Católica inscribe al desaparecido en otro lugar; lo hace presente e intenta reificarlo en el cuerpo del "no nacido". Por consiguiente, la alusión al Nunca Más con el propósito de instalar en la sociedad la idea del aborto como una práctica atravesada por el horror y la tortura guarda relación al modo con que la labor de encuadramiento de la memoria logra despertar un cúmulo de sensibilidades éticas y morales. "Con la experiencia amarga de nuestra propia historia reciente, los argentinos deberíamos ser protagonistas en la lucha por los indefensos [...] 'Nunca más' no puede ser solamente el título de un libro, sino debe ser el reclamo permanente frente a cualquier atropello a la vida" (Stockler et al., 2006) ${ }^{8}$.En cierto modo, nos encontramos frente a instancias coyunturales en donde el pasado es reelaborado significativamente de acuerdo a las expectativas del presente (Traverzo, 2007: 67). En otras palabras, momentos en donde la memoria es activada a fin de comprender situaciones nuevas con agentes sociales, políticos e institucionales diferentes ${ }^{9}$. Circunstancias en la que los actores sociales interesados en resignificar los sentidos del pasado se interesan en hacer un uso ejemplar de la memoria (Todorov, 2000; Jelin, 2002):

Honestamente me aterra como ciudadano escuchar -actualmente- expresiones similares a las que escuchaba en boca de los responsables de torturas, muerte y desapariciones de personas, en décadas pasadas. Hoy escucho que para defender la libertad de la mujer se pretende legitimar la "interrupción del embarazo no deseado". Ayer se pretendió legitimar la tortura hasta la muerte, para descubrir un posible atentado y así salvar centenares de vidas [...] Me aterra -repito- que en la Argentina actual, el genial y sabio NUNCA MAS no haya llegado ha erradicar el nefasto principio de que el fin justifica los medios [...] Una aclaración más: tampoco el tema del aborto es "cuestión religiosa". El aborto provocado es un crimen de lesa humanidad porque viola un fundamental derecho humano (Hesayne et al., 2009). ${ }^{10}$

\footnotetext{
${ }^{8}$ Monseñor Luis Stockler, obispo de Quilmes, Buenos Aires, Argentina.

9 Por consiguiente, la resignificación de la memoria y el pasado reciente nos lleva a plantearnos sobre las estrategias de la Iglesia Católica a nivel de sus actores y discursos; cuyo propósito se centra en la posibilidad de operar con mayor eficacia en el espacio democrático. Las formas con que dicha institución intenta políticamente incidir sobre las políticas públicas -específicamente los debates por el reconocimiento de los derechos sexuales y reproductivos y la legalización del aborto- nos conduce a abordar lo religioso no como una dimensión en retirada, sino a hacer hincapié en las mutaciones y cambios en el catolicismo a nivel de sus estrategias. En otras palabras, pensar a la Iglesia Católica como una institución que se erige además como política y que por tanto hace a la complejidad del sistema democrático.

${ }^{10}$ Monseñor Miguel. E. Hesayne, obispo emérito de Viedma, Rio Negro, Argentina.
} 
La reminiscencia a los años de la dictadura y el intento de colocar al debate del aborto en la narrativa del Nunca Más, no es más que el empleo de un mecanismo político de interpelación social en tanto se acude a los crímenes del pasado para, así, despertar conciencia sobre la valorización del derecho de la vida. El Nunca Más, vehículo de activación de la memoria para la Iglesia Católica y tropo discursivo en el que se inscribe parte de los argumentos en contra de la legalización del aborto, adquiere en el presente la función de un imperativo moral. La construcción imaginaria de un presente que -como en el pasado- vuelve a atentar contra el derecho a la vida:

Este "permiso para matar", aunque se lo quiera maquillar con palabras mentirosas, esas muertes de niños, ¿no serían verdaderos "crímenes de lesa humanidad”, promovidos e impulsados por el mismo Estado? ¿Dónde quedan los derechos humanos, a veces tan “cacareados” por más de uno que propugna estas matanzas? ¿En qué tacho de basura de la conciencia se tira el primero de los derechos humanos: "el derecho a vivir"? [...] Ya lo sufrimos bastante en su momento y fuimos capaces de decir, con toda fuerza y convicción: ¡NUNCA MÁS! Que “nunca más” en este bendito país volvamos a repetir esos sucesos tan dolorosos de nuestra historia reciente (Delgado, 2010) ${ }^{11}$.

Desde otro plano, es posible observar el modo en que el Nunca Más toma cuerpo también en el accionar político del "Colectivo de Mujeres Juana Azurduy". En el marco de la "Campaña Nacional por el Derecho al Aborto Legal, Seguro y Gratuito"sus representantes recurren a la activación de dicho significante como una forma de irrumpir en el espacio público trayendo a colación la cercanía entre los hechos del presente y las injusticias cometidas en el pasado. ${ }^{12}$

En este sentido, el uso político e intento de resignificación del Nunca Más responde a la elaboración de una estrategia política que intenta operar en el marco de una sociedad que -con el devenir del tiempo- ha quedado sensible a todo aquello que tenga que ver con el recuerdo de la violencia y el horror. En este caso, la alusión

\footnotetext{
${ }^{11}$ Monseñor Alfonso Delgado, arzobispo de San Juan de Cuyo, San Juan, Argentina.

${ }^{12}$ La Campaña Nacional por el Derecho al Aborto Legal, Seguro y Gratuito, se lanzó en la cuidad capital de Córdoba en Mayo de 2005. En la oportunidad se reunieron representantes de más de 70 organizaciones del país con un petitorio bajo el lema "Educación sexual para decidir, anticonceptivos para no abortar, aborto legal para no morir". La campaña considera que la defensa del derecho al aborto es una razón de salud pública y es una causa justa en razón de su contenido democrático y de justicia social; lo que permite asegurar el goce de los derechos humanos a las mujeres. Asimismo propone, entre otros aspectos, despenalizar y legalizar el aborto para que las mujeres que decidan interrumpir un embarazo en las primeras doce semanas de gestación tengan atención segura y gratuita en los hospitales públicos y obras sociales de todo el país.
} 


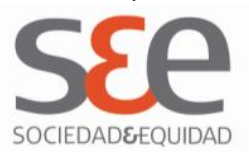

a la existencia de una proliferación de mujeres que -a la luz de nuestros díasvuelven a morir en el espacio de la clandestinidad, no hace más que reactivar el proceso de encuadramiento del pasado. La muerte en la "clandestinidad" -tema central bajo el que se encolumnan los argumentos a favor de la despenalización del aborto- hace reminiscencia a la idea de una sociedad inocente en la que los avasallamientos al derecho a la vida y la libre disposición del propio cuerpo estuvieron atravesados por el horror y el silencio: "La plena vigencia de los derechos humanos significa condenar a los genocidas de ayer, porque es parte de una lucha en la que estamos plenamente comprometidas, como garantizar el pleno derecho de las mujeres a decidir sobre sus cuerpos [...] Quienes niegan el derecho al aborto legal, no hacen más que promover su clandestinidad" (Campaña Nacional por el Derecho al Aborto Legal, Seguro y Gratuito et al., 2010) ${ }^{13}$.

La apelación a la memoria del Nunca Más habilita a crear en el colectivo feminista una semántica política mediante la cual se juzgan circunstancias injustas para las mujeres; al mismo tiempo que actúa como una constante que justifica su accionar militante. En la medida en que el discurso de los derechos humanos y la memoria son apropiados por vastos sectores sociales -en este caso las feministas- lo que en realidad queda en claro es el potencial que dicho discurso tiene como dispositivo de interpelación social. Lo que caracteriza a las experiencias traumáticas de las sociedades no radica únicamente en la dislocación que el pasado ha provocado sobre aquellos sujetos que han sido víctimas presenciales de la violencia y el horror los huecos, los silencios, la imposibilidad de comunicar- sino también, en el impacto cultural que dicha experiencia fue generando sobre la sociedad; un impacto que, en cierto modo, guarda relación con el tipo de lenguaje y con el marco cultural interpretativo en el que dicha experiencia se expresa (Jelin, 2000). La demanda por la despenalización del aborto se inscribe en el marco de la construcción social y recepción de tal experiencia. En este caso, el Nunca Más no sólo actúa como una consigna política que retrotrae y mantiene latente los recuerdos traumáticos del pasado; sino que es instrumentado como un significante político cuyo fin es darle visibilidad y trascendencia pública a la demanda por el derecho al aborto:

La sanción de una ley que legalice la interrupción voluntaria del embarazo en la Argentina es una cuestión de necesidad y urgencia, de justicia social y derechos humanos: una deuda pendiente con las mujeres. Los abortos clandestinos son la principal causa de mortalidad materna en nuestro país [...] Legalizar el aborto es hablar de igualdad, de igualar derechos entre quienes tienen el dinero para interrumpir un embarazo en una clínica privada y quienes

13 "Cuando los derechos humanos no llegan a las humanas", Campaña Nacional por el Derecho al Aborto Legal, Seguro y Gratuito, Buenos Aires, 27 de Julio de 2010. 


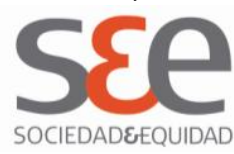

utilizan métodos caseros. Todas abortamos en la clandestinidad pero las que mueren son las mujeres más pobres y jóvenes. Legalizar el aborto es atender una situación que nos atraviesa como sociedad, es garantizar a las mujeres el derecho a decidir sobre su propio cuerpo sin correr el riesgo de perder la vida en ello. La penalización es absurda ya que las mujeres no son criminales [...] Señores diputados y diputadas de la Nación. Es hora de tratar el proyecto de ley de interrupción voluntaria del embarazo. Abortos clandestinos NUNCA MÁS (Colectivo de Mujeres Juana Azurduy et al., 2010) ${ }^{14}$.

En síntesis, podemos decir que en la disputa que la Iglesia Católica, los militantes pro-vida y el colectivo feminista emprenden en torno a la legalización o no del aborto encontramos la capacidad de agencia de estos actores sociales para hacer un uso político de la memoria, su resignificación simbólica y desplazamiento en el tiempo; así como la conversión del Nunca Más en un dispositivo moral de interpelación. Ahora bien, ello guarda relación con el modo en que la labor de encuadramiento de la memoria ha ido estructurando los procesos de rememoración del pasado; la forma en que la construcción imaginaria de una sociedad inocente se ha ido transformando en una clave cultural de lectura respecto a los años de la dictadura. En este sentido, los “niños por nacer”, así como las mujeres que mueren a causa de la práctica clandestina del aborto, representan -para quienes se encuentran en los extremos de esta disputa- la existencia de nuevas víctimas inocentes en los tiempos de democracia, un nuevo avasallamiento sobre el derecho humano a la vida, la repetición de los años del horror. En fin, qué es este uso político del Nunca Más sino el intento de involucrar moral y éticamente a la sociedad en la disputa por el aborto. "La memoria opera como puente que, articulando dos orillas diferentes, sin embargo las conecta" (Calveiro, 2006: 377). Es en esa articulación precisa donde reside la carga moral y política que se le asigna a la memoria de la última dictadura militar en la Argentina.

\section{Consideraciones finales}

En la Argentina de los últimos años,la legalización del aborto se ha transformado en un tema de debate que involucra una diversidad de actores sociales, políticos e institucionales. En alusión a ello, el interés de este ensayo ha sido abordar la disputa que la Iglesia Católica, los militantes pro-vida y la corriente feminista mantienen con relación a la definición y defensa de la vida. En efecto, nuestro interés fue prestar atención a la elaboración de distintas prácticas y estrategias discursivas por parte de dichos actoresa fin de dividir y antagonizar el campo político y social respecto a dicha temática. Por ende, es que nos ocupamos en focalizar las estrategias de

\footnotetext{
14 "Solicitada por la despenalización del aborto", Colectivo de Mujeres Juana Azurduy,
} Buenos Aires, 28 de Setiembre de2010. 


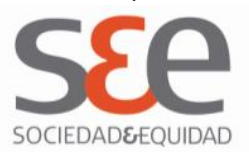

reapropiación y resignificación discursiva de ciertos componentes discursivos ligados al imaginario político y social de la memoria de los años de dictadura en Argentina terrorismo de Estado, crímenes de lesa humanidad, inocentes desaparecidos, muertes en la clandestinidad, violación de los derechos humanos y en especial la narrativa política del Nunca Más- y su asociación a la defensa de la vida del "no nacido" o de la mujer gestante. Esto es, la construcción discursiva que la Iglesia Católica y los militantes pro-vida hacen del aborto como la instrumentación de nuevas metodologías de tortura y muerte en el contexto democrático; así como la alusión por parte de sectores del feminismo a las miles de muertes de mujeres pobres a causa del aborto clandestino en reminiscencia a las muertes que en el pasado se dieron -también- en el marco del silencio y la clandestinidad.

En este sentido, y a partir de la experiencia social y colectiva que marcó la dictadura en la Argentina, podemos decir que la memoria se hace presente en el ejercicio de un doble movimiento. Por un lado, en la preocupación por mantener latente los acontecimientos del pasado dictatorial; por el otro, en el uso político que las significaciones de ese pasado tiene con relación a los propósitos inmediatos del presente y los deseos de proyecciones futuras. Pues, el reconocimiento de la memoria como objeto de disputa, conflictos y luchas -en este caso la disputa entre católicos y feministas por la resignificación discursiva de la narrativa política y cultural del Nunca Más y su vinculación con la temática del aborto- nos lleva a prestar atención al rol activo y productor de sentidos que la instrumentación misma de la memoria adquiere en el escenario del presente. En base a considerar de qué modo los debates y tensiones en torno al aborto pretenden políticamente ser inscriptos en estructuras de sentidos prexistentes, recobramos -para los fines de este análisis- la centralidad y vigencia que la memoria tiene en el proceso de interacción social en tanto práctica reflexiva y de interpretación de los acontecimientos actuales.

\section{Referencias Bibliográficas}

Bredice, Reinaldo(2007). "Repudió a la ley provincial de abortos no punibles". Agencia de Información Católica Argentina (AICA). [Documento en línea].

Disponible en Internet:

<http: / / www.aica.org/index.php?module=displaystory\&story_id=10269\&format=print $>$

Castellano, Roberto (2010). "El aborto es un verdadero acto de terrorismo de estado". Información Católica. Información, análisis y opinión en la red. [Documento en línea]. 
Disponible desde Internet en: <http://infocatolica.com/?t=noticia\&cod=5820>

Calveiro, Pilar (2006). “Los usos políticos de la memoria”. En Gerardo Caetano (Comp.), Sujetos sociales y nuevas formas de protesta en la historia reciente de América Latina (pp. 359-382). Buenos Aires: CLACSO.

Campaña Nacional por el Derecho al Aborto Legal, Seguro y Gratuito (2010), “Cuando los derechos humanos no llegan a las humanas". Campaña Nacional por el Derecho al Aborto Legal, Seguro y Gratuito/ sitio web. [Documento en línea]. Disponible desde Internet en: <http://www.abortolegal.com.ar/?p=665>

Cerrutti, Gabriela (2001). "Entre la fetichización y el duelo. La historia de la memoria”. Puentes, año 1, N³, Buenos Aires, Marzo de 2001: 14-25.

Colectivo de Mujeres Juana Azurduy (2010). "Solicitada por la despenalización del aborto". Las Juanas/ sitio web. [Documento en línea]. Disponible desde Internet en: <http://www.lasjuanas.org.ar/>

Crenzel, Emilio (2005). “El testimonio en una memoria ciudadana: el informe Nunca Más”. Estudios. Revista del Centro de Estudios Avanzados, N16, otoño del 2005, Universidad Nacional de Córdoba: 31-47.

Crenzel, Emilio (2008).La historia política del Nunca Más. La memoria de las desapariciones en la Argentina. Buenos Aires: Siglo XXI.

Crenzel, Emilio (2010). "La víctima inocente: de la lucha antidictatorial al relato de Nunca Más". En Emilio Crenzel (Coord.), Los desaparecidos en la Argentina. Memorias, representaciones e ideas (1983-2008) (pp 65-83). Buenos Aires: Biblos.

Da Silva Catela, Ludmila (2010). "Pasados en conflicto. De memorias dominantes, subterráneas y denegadas". En Ernesto Bohoslavsky, Marina Franco y Daniel Lvovich (Comps.), Problemas de historia reciente del Cono Sur (Volumen I) (pp. 99-125). Buenos Aires: Prometeo/Universidad Nacional de General Sarmiento. 
Delgado, Alfonso (2010). “Culminación de año jubilar de la Arquidiócesis de San Juan de Cuyo". Agencia de Información Católica Argentina (AICA). [Documento en línea]. Disponible desde Internet en: <http://www.aica.org/docs_blanco.php?id=640>

Gonzáles Bombal, Inés (1995). “Nunca Más. El juicio mas allá de los estrados”. En AA.VV. Juicio, Castigos y memorias. Derechos humanos y justicia en la política argentina (pp. 195-215). Buenos Aires: Nueva Visión.

Halbwachs, Maurice (2004).Los marcos sociales de la memoria. Barcelona: Anthropos.

Halbwachs, Maurice (2004). Los marcos sociales de la memoria. Barcelona: Anthropos. (2005), "Memoria individual y memoria colectiva”. Estudios. Revista del Centro de Estudios Avanzados, $\mathrm{N}^{\circ}$ 16, otoño del 2005, Universidad Nacional de Córdoba: 163-186.

Hesayne, Miguel E. (2009). “El aborto es un crimen de lesa humanidad”.Agencia de Información Católica Argentina (AICA). [Documento en línea].

Disponible desde Internet en: <http://www.aica.org/index.php?module=displaystory\&story_id=18561\&edition_id=1 096\&format=html\&fech=2009-09-27>

Huyssen, Andreas (2001). En busca del futuro perdido. Cultura y memoria en tiempos de globalización. México: Fondo de Cultura Económica.

Jelin, Elizabeth (2000). “Memorias en conflicto”.Puentes, año 1, $\mathrm{N}^{\circ} 1$, Buenos Aires, Agosto de 2000: 6-13.

Jelin, Elizabeth (2002). Los trabajos de la memoria. Buenos Aires: Siglo XXI.

Jelin, Elizabeth(2007). “La conflictiva y nunca acabada mirada sobre el pasado”. En Marina Franco y Florencia Levín (Comps.), Historia reciente. Perspectivas y desafíos para un campo en construcción (pp. 307-340). Buenos Aires: Paidós. 
Levín, Florencia (2005). “Arqueología de la memoria. Algunas reflexiones a propósito de los vecinos del horror. Los otros testigos". Entrepasados. Revista de historia, N ${ }^{\circ}$ 28, Buenos Aires, 2005: 47-63.

Lvovich, Daniel y Jaqueline Bisquert (2008). La cambiante memoria de la dictadura. Discursos públicos, movimientos sociales y legitimidad democrática. Buenos Aires: Universidad Nacional de General Sarmiento/Biblioteca Nacional.

Nancy, Jean-Luc (2006). Noli me tangere. Ensayo sobre el levantamiento del cuerpo. Madrid: Trotta.

Pollak, Michael (2006). Memoria, olvido y silencio. La producción social de identidades frente a situaciones límites. La Plata: Ediciones Al Margen.

Ramos, Ramón (1989). “Maurice Halbwachs y la memoria colectiva”. Revista de Occidente, $\mathrm{N}^{\circ}$ 100, Madrid 1989: 63-81.

Rousso, Henry (1991). “Pour une histoire de la mémoire collective: l'après Vichy”. En Denis Peschansky, Michel Pollak y Henry Rousso (Eds.), Histoire politique et sciences sociales.Paris: Complexe.

Rousso, Henry (2000). "El duelo es imposible y necesario". Entrevista de Claudia Feld. Puentes, año 1, N², Buenos Aires, Diciembre de 2000: 30-39.

Sábato, Ernesto (1984). “Prólogo”. En CONADEP, Nunca Más. Informe de la Comisión Nacional sobre la Desaparición de Personas (pp. 3-7). Buenos Aires: EUDEBA.

Stoclker, Luis (2006). “Nunca Más no puede ser solamente el título de un libro". Agencia de Información Católica Argentina (AICA). [Documento en línea]. Disponible desde Internet en: <http://www.aica.org/index2.php?pag=stockler060730>

Todorov, Tzvetan (2000). Los abusos de la memoria. Barcelona: Paidós. 


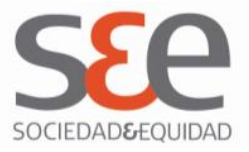

Traverso, Enzo (2007). "Historia y memoria. Notas sobre un debate". En Marina Franco y Florencia Levín (Comps.), Historia reciente. Perspectivas y desafíos para un campo en construcción (pp. 67-96). Buenos Aires: Paidós.

Vezzetti, Hugo (2003). Pasado y presente. Guerra, dictadura y sociedad en la Argentina. Buenos Aires: Siglo XXI. 